\title{
Minining
}

http://dx.doi.org/10.1590/0370-44672018720004

Paulo Renato Perdigão de Paiva ${ }^{2,3,5}$

http://orcid.org/0000-0001-5538-2040

Ângela Mello Ferreira ${ }^{2,3,6}$

Gabriela Cordeiro Silva ${ }^{3,7}$

Virgínia Sampaio Teixeira Ciminelli ${ }^{1,3,8}$

Peter Georg Weidler ${ }^{3,4,9}$

${ }^{1}$ Universidade Federal de Minas Gerais - UFMG, Departamento de Engenharia Metalúrgica e de

Materiais, Belo Horizonte - Minas Gerais - Brasil.

${ }^{2}$ Centro Federal de Educação Tecnológica de Minas Gerais - CEFTMG, Departamento de Engenharia de

Materiais, Belo Horizonte - Minas Gerais - Brasil.

${ }^{3}$ Instituto Nacional de Ciência e Tecnologia em Recursos Minerais, Água e Biodiversidade, Belo Horizonte - Minas Gerais - Brasil.

${ }^{4}$ Karlsruhe Institute of Technology, Institute for

Functional Interfaces, Karlsruhe - Germany.

E-mails: ${ }^{5}$ paulorenato.paiva@gmail.com, 6angelamelo44@gmail.com, ${ }^{7}$ gcsilva25.gc@gmail.com, ${ }^{8}$ ciminelli@demet.ufmg.br, ${ }^{9}$ peter.weidler@kit.edu

\section{Evaluation of the Rietveld method for the mineralogical characterization of airborne dust in a mining area}

\section{Abstract}

In this article, we present the results of the mineralogical quantification of airborne dust from an urban area located in the Brazilian state of Minas Gerais in the vicinity of a gold mine. Three samples were collected at different points to assess spatial consistency. Results showed that the mineralogy, in relation to both major minerals and accessory minerals, is very similar for all samples, being predominantly composed of muscovite and quartz, which together account for around $60 \%$ to $75 \%$ by weight. The accessory minerals are clinochlore, albite, dolomite, calcite and kaolinite and the averages for each range from $4 \%$ to $13 \%$. The only trace mineral with concentration below $1 \%$ was pyrite which has a concentration below $1 \%$. The results provide an indication that the mining area is not the sole source of local dust, although the mine's contribution is significant.

keywords: Rietveld Method; X-ray diffraction; airborne dust.

\section{Introduction}

Airborne dust is generated naturally by wind erosion and also by sources, such as industry, agriculture, mining, transport, civil construction and housing, which may be unfavorable to air quality. The main causes of atmospheric pollution in urban areas are emissions caused from automobiles and industries (Toledo et al., 2008).

Identification of the chemical composition, morphology and mineralogy of airborne particulate matter (PM) is important for a better understanding of their properties and health risks. To investigate the toxicity of airborne particles, it is very important to know their morphological and crystallochemical characteristics. Chemistry and mineralogy provide fundamental data for pollutant specification and determination of their origin. Not all minerals in the airborne dust cause health problems for humans. But, airborne dust containing crystalline silica and asbestos represent health risks (Fubini and Fenoglio, 2007). Other minerals like hydroxides, talc, kaolinite, smectites and mica can also represent health risks, if the exposure is extended and with a certain intensity (Plumlee and Ziegler, 2003).

This study was focused on mineralogical quantification using X-ray diffraction data (XRD) combined with the Rietveld method for quantitative data refinement. The Rietveld method was originally developed for the refinement of crystal structures using data from X-ray or neutron diffraction (Rietveld, 1969). This analysis permits the identification and quantification of the mineral phases, such as phosphates, silicates and carbonates (Deysel, 2007). The method 
is a mathematical fit between the diffraction pattern obtained from an unknown sample and a reference pattern calculated from standard data, with the difference between real and calculated value points and calculations minimized by the least square method. The crystallographic databases (ICSD, LPF, NIST and CSD) provide the calculated standard. These databases provide the space group, atomic positions

\section{Materials and methods}

Glass filters coupled with highvolume samplers were used to collect the airborne dust samples (Hayward et al., 2010). Air was pumped through the filter for 24 hours, in compliance with the Brazilian National Air Quality Monitoring standards (CONAMA No. 003/1990). Three samples were collected at different locations for comparison. The PM-A sample PM-A (latitude $17^{\circ} 08^{\prime} 58.62^{\prime \prime S}$ and longitude $\left.46^{\circ} 49^{\prime} 56.71^{\prime} \mathrm{W}\right)$ was collected $8 \mathrm{~km}$ from the urban area and the PM-B (latitude 17'12'25.80"S and longitude 46'53'13.10"W) and PM-C (latitude $17^{\circ} 12^{\prime} 33.15^{\prime \prime S}$ and longitude 46053'41.10"W) samples were collected in the urban area. The PM-A sample is from upwind of the mine pit, and recent atmospheric particle dispersion modelling show that this area has the lowest par-

\section{Results and discussions}

Table 1 shows the results for semiquantitative elemental analysis obtained by XRF. Samples PM-A, PM-B and PM-C contain predominantly silicon, aluminum, calcium, potassium and sodium. The high concentrations of barium and zinc, approximately 5.0\% $\mathrm{BaO}$ and $1 \% \mathrm{ZnO}$ for all samples, are due to contamination from the glass

\begin{tabular}{|c|c|c|c|}
\hline \multirow[t]{2}{*}{ Oxides } & \multicolumn{3}{|c|}{ Samples } \\
\hline & PM-A (wt-\%) & PM-B (wt-\%) & PM-C (wt-\%) \\
\hline $\mathrm{SiO}_{2}$ & $68.7(0.1)$ & $68.0(0.3)$ & $64.0(0.2)$ \\
\hline $\mathrm{Al}_{2} \mathrm{O}_{3}$ & $13.9(0.1)$ & $14.3(0.1)$ & $15.3(0.2)$ \\
\hline $\mathrm{BaO}$ & $5.4(0.2)$ & $5.3(0.3)$ & $5.4(0.2)$ \\
\hline $\mathrm{K}_{2} \mathrm{O}$ & $3.6(0.1)$ & $3.4(0.1)$ & $3.1(0.1)$ \\
\hline $\mathrm{CaO}$ & $2.6(0.1)$ & $2.7(0.1)$ & $2.8(0.1)$ \\
\hline $\mathrm{Na}_{2} \mathrm{O}$ & $2.4(0.2)$ & $2.9(0.3)$ & $5.0(0.2)$ \\
\hline $\mathrm{SO}_{3}$ & $1.4(0.2)$ & $1.4(0.2)$ & $1.3(0.2)$ \\
\hline $\mathrm{ZnO}$ & $1.0(0.1)$ & $1.0(0.1)$ & $1.0(0.1)$ \\
\hline $\mathrm{MgO}$ & $0.5(0.1)$ & $0.5(0.1)$ & $1.6(0.1)$ \\
\hline $\mathrm{Fe}_{2} \mathrm{O}_{3}$ & $0.5(0.1)$ & $0.5(0.1)$ & $0.5(0.1)$ \\
\hline
\end{tabular}

and occupation positions. To apply the method, XRD data are used as obtained from the diffractometer. The advantage of this method is the fact that it employs all the points of the XRD diffractogram obtained and considers overlapping peaks (Rietveld, 1969).

This article aims to illustrate the application of Rietveld refinement in directly quantifying the phases present

ticulate concentration. The samples PM-B and $\mathrm{PM}-\mathrm{C}$ include the monitoring stations situated within close proximity to the active mine pit; these sites are immediately downwind of the mine and, thus, dust particles collected would be under direct influence of the mining operations.

SEM analyses were performed on a Shimadzu SSX-550 equipped with a secondary electron detector, which generated images for the morphology of the dust samples. For this purpose, the filters were coated with gold and analyses were performed with 1,000 times magnification.

XRD analyses were performed directly on the filters using a Shimadzu 7000 under the following operating conditions: $\mathrm{CuK} \alpha$ radiation $(35 \mathrm{KV} / 40 \mathrm{~mA})$, goniometer speed of $0.02^{\circ}$ per $2 \theta$ step, with a counting time of 5 seconds per step and a filters. XRF also showed the presence of low concentrations of sulfur, phosphorus and iron.

Figure 1 shows the SEM images. It should be noted that the dust is impregnated in the filter, and therefore the images show the filter fibers and the dust particles trapped within them. All the samples show similar morphology, in PM (airborne particulate matter). The X-ray diffraction (XRD) results are independently validated using scanning electron microscopy (SEM) with X-ray energy dispersive spectroscopy (EDS) and $\mathrm{X}$-ray fluorescence spectroscopy (XRF). As a case study, an urban center located $2 \mathrm{~km}$ from a large operating gold mine in the Brazilian state of Minas Gerais was selected for sample collection.

range from $7^{\circ}$ to $70^{\circ} 2 \theta$. Diffractogram interpretation was carried out by comparing standards contained in the PDF 02 database (ICDD, 2003).

The Rietveld refinement was carried out using the GSAS and interface EXPGUI program (Toby, 2001). The ThompsonCox-Hastings pseudo-Voigt profile function was used and the background was adjusted by the polynomial Chebyschev. Scale factor, unit cell, background radiation, profile asymmetry, the full width at half height from the instrumental broadening parameters obtained with a standard, atomic position and isotropic atomic displacements factors were refined. The values for $\mathrm{R}_{\mathrm{p}}$ and $\chi^{2}$ and the graphs obtained at every 3 cycles of refinement were measured to check the quality of the refinement and for a better monitoring of the results. irregular agglomerates and platelets typical of phyllosilicates (Bourotte et al., 2006; Cultrone et al., 2005), indicating that the major phases are likely to be the same. Based on a rapid visual assessment, sample PM-C contains a larger volume of particles adhered to the filter, which is consistent with its location downwind of the city.

Table 1

Semi-quantitative chemical analysis obtained by XRF for samples PM-A, PM-B and PM-C. 


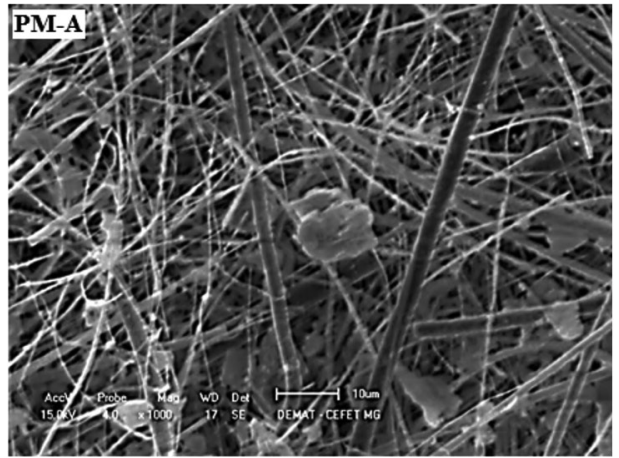

Figure 1

SEM images showing the morphology of airborne particles in samples PM-A, PM-B and PM-C.

Considering the urban activities in the sampling area, initially the samples were expected to be comprised mainly of particles originating from the combustion of fossil fuels or wood, since sample collection was performed in the period of drought, when forest fires often occur in regions with a semi-arid climate. Based on the descriptions by Pósfai and Buseck (2010), the particles observed in the samples probably were not formed during the processes mentioned above as these processes produce large agglomerates of spherical nanoparticles with uniform size.

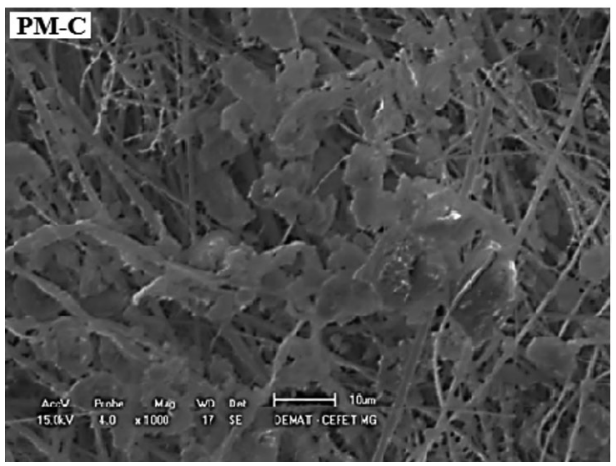

Results for XRD and Rietveld refinement are shown in Figures 2, 3 and 4. The main constituents, with the corresponding ICDD reference numbers, of the samples are quartz (83-0539), muscovite (80-0743), kaolinite (79-1570), clinochlore (20-0671), albite (71-1156), calcite (86-2339), dolomite (84-2065) and pyrite (71-0053). The curved shape of the diffractogram baselines is due to the amorphous filter paper. As amorphous phases generate no diffraction peaks, the Rietveld method treats the sample as if it only contains crystalline phases. The presence of amorphous
Figure 2

Diffractogram showing the results of the refinement of sample PM-A.

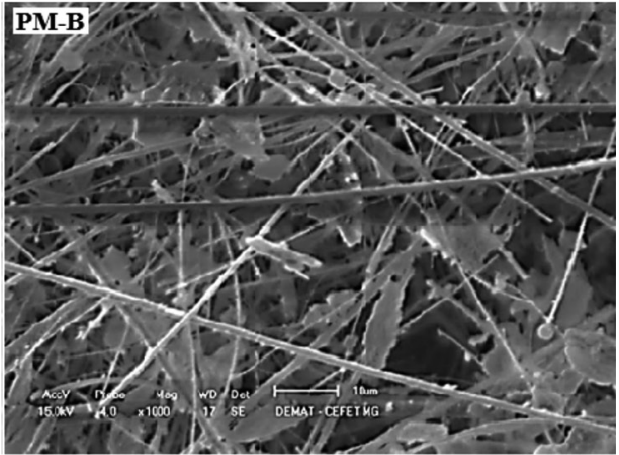

substances, however, does not influence the results of the refinement because the background due to amorphous phases is subtracted from the baseline of the diffractogram before the refinement. The proposal to solve this problem in future sampling would be to increase the filter's time of exposure in order to allow a thicker layer of matter adhered to the filter. This thicker layer would increase the portion of the plated sample (volume analyzed) through X-rays and, thereby, it would decrease the characteristic amorphousness of the filter paper.

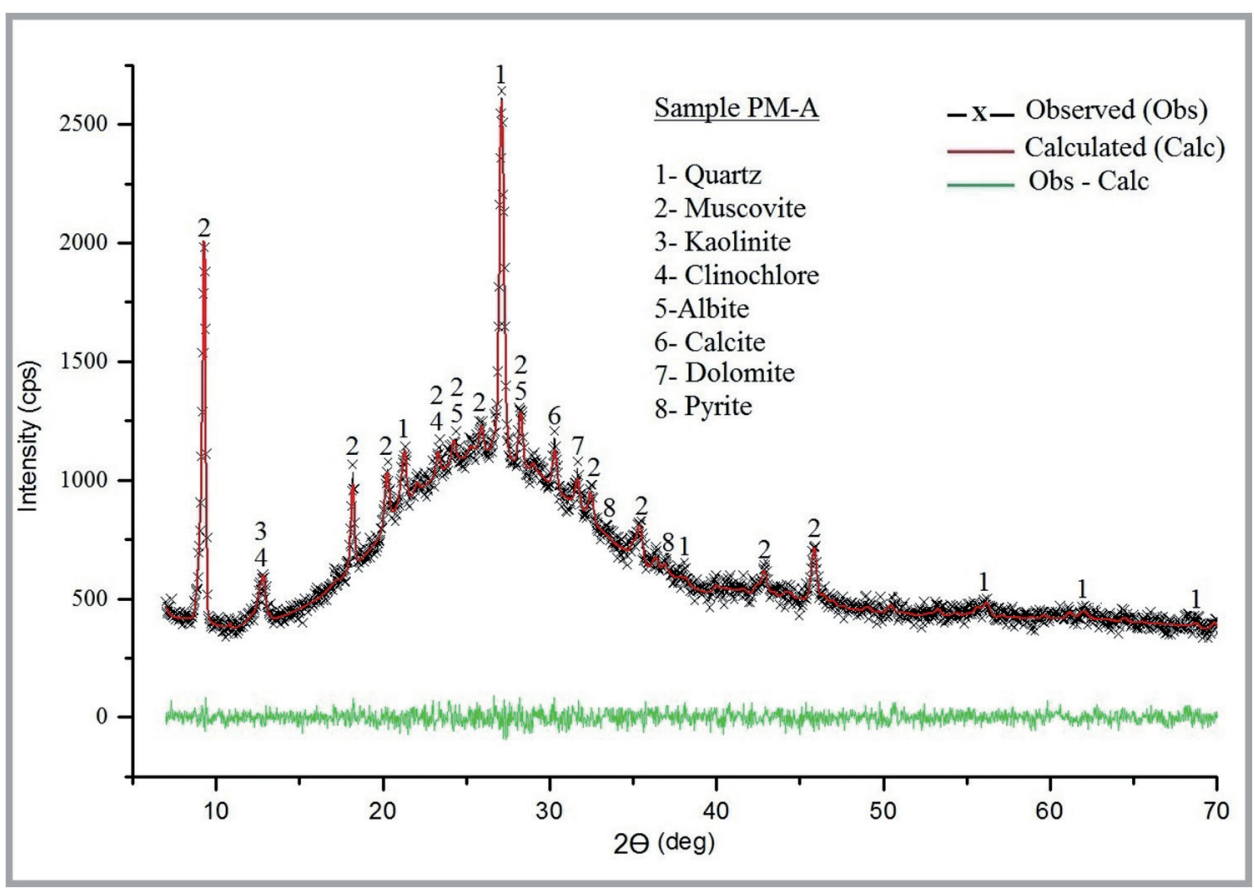



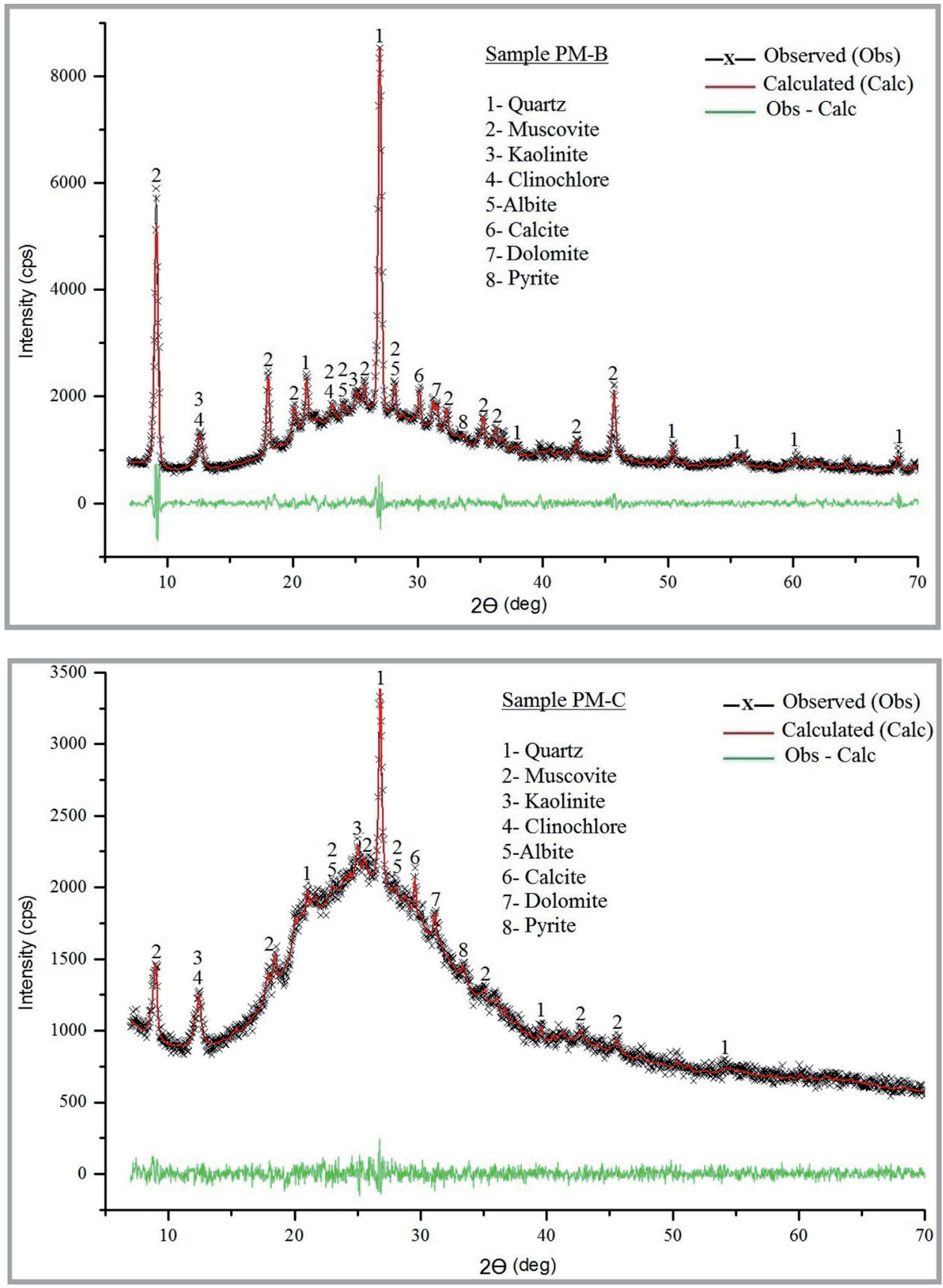

Table 2 shows the quantification of the mineralogical composition obtained from the Rietveld refinement. The mineralogy in terms of major, minor and trace minerals is very similar in the three samples, and consists predominantly of

\begin{tabular}{c|c|c|c}
\multirow{2}{*}{ Phases } & \multicolumn{3}{|c}{ Samples } \\
\cline { 2 - 4 } & PM-A (wt\%) & PM-B (wt\%) & PM-C (wt\%) \\
\hline Quartz & $50.9(0.4)$ & $48.7(0.2)$ & $23.3(0.2)$ \\
\hline Muscovite & $19.9(0.2)$ & $28.6(0.1)$ & $4.8(0.2)$ \\
\hline Calcite & $3.1(0.3)$ & $1.4(0.2)$ & $3.3(0.3)$ \\
\hline Dolomite & $3.2(0.4)$ & $1.2(0.1)$ & $14.0(0.6)$ \\
\hline Kaolinite & $6.8(0.5)$ & $5.1(0.3)$ & $5.8(0.2)$ \\
\hline Clinochlore & $11.0(0.4)$ & $6.9(0.3)$ & $9.0(0.5)$ \\
\hline Albite & $4.2(0.2)$ & $7.4(0.4)$ & $<1.0$ \\
\hline Pyrite & $<1.0$ & $<1.0$ &
\end{tabular}

Figure 3

Diffractogram showing the results of the refinement of sample PM-B.

Figure 4

Diffractogram showing the results of the refinement of sample PM-C.

The only trace mineral with concentration below $1 \%$ is pyrite. The presence of trace minerals should be assessed using other techniques, such as electron microscopybased automated analysis.

Table 2

XRD and Rietveld refinement results. 
The efficiency of the Rietveld method is verified through numerical indicators evaluated during and after refinement in order to verify if the results are satisfactory (Post and Bish, 1989). The numerical indicators used for the GSAS program are $\mathrm{Rp}$ (profile factor) and $\chi^{2}$. The $\chi^{2}$ parameters calculated for samples PM-A, PM-B and PM-C was $1.4 \%, 2.8 \%$ and $1.3 \%$, respectively. The $\chi^{2}$ value should be $1.0 \%$ in a flaw-

Table 3

Comparison between the chemical analyses calculated

from the Rietveld method (XRD) and those obtained by XRF.

The difficulty in the comparison between the calculated and real chemical composition is to determine the quantity of volatile materials present in the sample before analysis of XRF. The volatile materials present in these samples can be pore water, $\mathrm{OH}$ - in hydroxides, carbonates and sulfides (compounds non-structural and structural), which are probably removed during heating in the

\section{Conclusions}

This study shows that the Rietveld refinement has a great potential for the quantification of the main mineral phases present in airborne dust. Trace components can also be detected, however, their presence and quantity may need to be confirmed using other techniques.

It is important to reaffirm that in this study, the airborne dust samples were analyzed directly on filter paper impregnated with particles without prior preparation.

\section{Acknowledgments}

The authors would like to thank Dr. Massimo Gasparon (University of Queensland, School of Earth Sciences - less refinement, but normally values below $5.0 \%$ indicate a good refinement (Mccusker et al., 1999). The Rp setting parameters calculated for samples PMA, PM-B and PM-C was $3.4 \%, 3.6 \%$ and $2.5 \%$, respectively. These values are larger than those obtained for the refinement of simple mineral phases, but fall within the range observed for natural multi-mineral systems, as demonstrated by Hill et al. (1993), Mumme et al.

(1996) and Weidler et al. (1998).

Accuracy verification of mineral measurements through the Rietveld method is carried out by comparison with another independent method. Table 3 shows the results obtained using the Rietveld method (XRD) compared with those obtained by XRF for major oxides (total sum of oxides based only on $\mathrm{SiO}_{2}, \mathrm{AlO}_{3}, \mathrm{CaO}, \mathrm{K}_{2} \mathrm{O}$ and $\mathrm{Na}_{2} \mathrm{O}$; $\Sigma$ phases $80 \%$ ).

\begin{tabular}{c|c|c|c|c|c|c}
\multirow{2}{*}{ Oxides } & \multicolumn{6}{|c}{ Samples } \\
\cline { 2 - 7 } & \multicolumn{3}{|c|}{ XRD (\%) } & \multicolumn{3}{c}{ XRF (\%) } \\
\cline { 2 - 7 } & PM-A & PM-B & PM-C & PM-A & PM-B & PM-C \\
\hline $\mathrm{SiO}_{2}$ & 66.4 & 69.5 & 62.3 & 68.6 & 67.8 & 64.0 \\
\hline $\mathrm{Al}_{2} \mathrm{O}_{3}$ & 12.6 & 13.8 & 16.4 & 13.9 & 14.4 & 12.8 \\
\hline $\mathrm{CaO}$ & 2.2 & 1.7 & 3.1 & 2.6 & 2.4 & 2.7 \\
\hline $\mathrm{K}_{2} \mathrm{O}$ & 3.4 & 5.2 & 5.1 & 3.6 & 3.4 & 3.2 \\
\hline
\end{tabular}

pre-treatment for XRF analyzes. It is difficult to calculate the loss of these volatile materials, therefore this was ignored. To correct for the influence of volatile structural components in the XRF analysis, the composition was calculated from the oxides present in the minerals.

Also, in the case of these samples, a comparison is very difficult to be made, since different phases compete for the same elements and also because chemical analysis through XRF was performed by the semi-quantitative method. Yet, despite the lack of an accurate phase analysis through XRF, the results are consistent, as can be seen in Table 3. These results are an indication that the quantification by X-ray diffraction combined with the Rietveld method is very promising for the characterization of PM.
Relatively rapid identification and quantification were achieved, allowing to evaluate the main dust sources.

The use of the Rietveld method in the quantitative phase analysis offers advantages over traditional analytical methods through integrated intensity. This is due to: i) use of the overall diffractometric pattern, reducing the systematic effects of preferred orientation; ii) a more effective treatment of overlapping peaks; iii) refinement of the crystalline structure and peak parameters for individual phases; iv) background adjustment; and v) adjustment of preferred orientation for each phase.

The efficiency of the Rietveld method facilitates its use in comparison to other methods. However care should be taken because to perform crystal structure analysis based on X-ray diffraction data requires greater knowledge in crystallography.
Brisbane, Australia), Conselho Nacional de Desenvolvimento Científico e Tecnológico (CNPq), Coordenação de Aperfeiçoamento de Pessoal de Nível Superior (CAPES) and Fundação de Amparo à Pesquisa do Estado de Minas Gerais (FAPEMIG).

\section{References}

BOUROTTE, C., FORTI, M. C., MELFI, A. J., LUCAS Y. Morphology and solutes content of atmospheric particles in an urban and a natural area of São Paulo state, Brazil. Water, Air, and Soil Pollution, v. 170, p. 301-316, 2006.

CONAMA N ${ }^{\circ}$ 003. 1990. Conselho Nacional de Meio Ambiente. Available in: http:// www.mma.gov.br/port/conama. Access 11/21/2017.

CUltrone, G. E., SEBASTI-AN, E., DELA TORRE, M. J. Mineralogical and 
physical behavior of solid bricks with additives. Construction and Building Materials, v. 19, p. 39-48, 2005.

DEYSEL, K. Leucoxene study: a mineral liberation analysis (MLA) investigation. In: INTERNATIONAL HEAVY MINERALS CONFERENCE 'BACK TO BASICS', 6. Johannesburg: The Southern African Institute of Mining and Metallurgy, 2007. p. $167-172$

FUBINI, B., FENOGLIO, I. Toxic potential of mineral dusts. Elements, v. 3, p. 407-414, 2007.

HAYWARD, S. J., GOUIN, T., WANIA, F. Comparison of four active and passive sampling tecniques for pesticides in air. Environmental Science and Technology, v. 44, n. 9, p. 3410-3416, 2010.

HILL, R. J., TSAMBOURAKIS, G., MADESEN, I. C. Improved petrological modal analysis from X-ray powder diffraction data by use of the Rietveld method. I. Selected igneous, volcanic, and metamorphic rocks. Journal of Petrology, v. 35, p. 867-900, 1993.

INTERNATIONAL Center for Diffraction Data, Powder Diffraction File 02 (PDF02), Release 2003. Available in: http://www.icdd.com/products/index.htm. Access 05/21/2017.

MCCUSKER, L. B., VON DREELE, R. B., COX, D. E., LOUER, D., SCARDI, P. Rietveld refinement guidelines. Journal of Applied Crystallography, v. 32, p. 36-50, 1999.

MUMME, W. G., TSAMBOURAKIS, G., MADSEN, I. C., HILL, R. J. Improved petrological modal analysis from X-ray powder diffraction data by use of the Rietveld method. II. Selected sedimentary rocks. Journal of Sedimentary Research, v. 66, n. 1, p. 132-138, 1996.

PLUMLEE, G. S., ZIEGLER, T. L. The medical geochemistry of dusts, soils, and other earth materials. In: LOLLAR, B. S. (ed.). Treatise on Geochemistry. Imprint, Elsevier Science, 2003. v. 9, cap. 9.07, p. 263-310. 612 p.

PÓSFAI, M., BUSECK, P. R. Nature and climate effects of individual tropospheric aerosol particles. Annual Review of Earth and Planetary Sciences, v. 38, p.17-43, 2010.

POST, J. E., BISH, D. L. Rietveld refinement of crystal structures using powder X-ray diffraction data. In: BISH, D. L., POST, J. E. (ed.). Modern powder diffraction. Washington, D.C.: The Mineralogical Society of America, 1989. v. 20, cap. 9, p. 277-308.

RIETVELD, H. M. A profile refinement method for nuclear and magnetic structures. Journal of Applied Crystallography, v. 2, p. 65-71, 1969.

TOBY, B. H. EXPGUI: a graphical user interface for GSAS. Journal Applied Crystallography, v. 34, p. 210-213, 2001.

TOLEDO, V. E., ALMEIDA JUNIOR, P. B., QUITERIO, S. L., ARBILLA, G., MOREIRA, A., ESCALEIRA, V., MOREIRA, J. C. Evaluation of levels, sources and distribution of toxic elements in PM10 in a suburban industrial region, Rio de Janeiro, Brazil. Environmental Monitoring and Assessment, v. 139, p. 49-59, 2008.

WEIDLER, P. G., LUSTER, J., SCHNEIDER, J., STICHER, H., GEHRING, A. U. The Rietveld method applied to the quantitative mineralogical and chemical analysis of a ferralitic soil. European Journal of Soil Science, v. 49, p. 95-105, 1998.

Received: 15 January 2018 - Accepted: 26 December 2018.. 